\title{
Knowledge, attitude and practice of exercise among patients with type 2 diabetes mellitus
}

\author{
Lavanya Devi Palaniswamy ${ }^{1, *}$
}

${ }^{1}$ Department of General Medicine, Vinayaka Mission's Kirupananda Variyar Medical College and Hospital, Salem, Tamil Nadu-636308, India

\begin{abstract}
Introduction: Exercise plays significant role in the health outcomes of patients with diabetes; however, little is known about the knowledge, attitude and practice of exercise in patients with type- 2 diabetes (T2D). This study investigated knowledge, attitude and practice of exercise among patients with type 2 diabetes.
\end{abstract}

Materials and methods: This cross-sectional study recruited 165 patients with T2D (male $=85$; female $=80$ ) using convenience sampling technique. Questionnaires were used to assess the knowledge, attitude and practice of exercise among patients. Data were analysed using descriptive and inferential statistics. Alpha level was set at $\mathrm{p}<0.05$.

Results: The mean age of respondents was $51.9 \pm 9.8$ years. A majority, $139(84.24 \%)$ were married individuals and around than half, 76(46.1\%) were in the low SES. One hundred and thirty (78.7\%) had good knowledge and attitude towards exercise practice. More than half, 95(57.6\%) engaged in regular exercise practice. There was significant association between knowledge and practice of exercise $(\mathrm{p}<0.05)$. No significant associations were found between knowledge and gender, and socioeconomic status ( $p>0.05$ ). Low physical activity was associated with poor glycemic control $(\mathrm{p}<0.05)$.

Conclusion: Patients demonstrated good knowledge and a positive attitude towards exercise and a relatively poor practice of exercise. Additional methods are needed to encourage regular physical activity among patients.

Keywords: type-2 diabetes mellitus; physical activity; exercise; knowledge; attitude; glycemic control

\footnotetext{
*Corresponding author: Dr. Lavanya Devi Palaniswamy, Assistant professor, Department of General Medicine, Vinayaka Mission's Kirupananda Variyar Medical College and Hospital, Salem, Tamil Nadu-636308, India. Mobile: 9944935355; Email: lavans_p@yahoo.com

Received 25 July 2020; Revised 22 August 2020; Accepted 2 September 2020; Published 10 September 2020

Citation: Palaniswamy LD. Knowledge, attitude and practice of exercise among patients with type 2 diabetes mellitus. J Med Sci Res. 2020; 8(4):145-149. DOI: http://dx.doi.org/10.17727/ JMSR.2020/8-19
}

Copyright: (C) 2020 Palaniswamy LD. Published by KIMS Foundation and Research Center. This is an open-access article distributed under the terms of the Creative Commons Attribution License, which permits unrestricted use, distribution, and reproduction in any medium, provided the original author and source are credited. 


\section{Introduction}

Chronic non-communicable diseases are the leading cause of morbidity and mortality worldwide $[1,2]$. Among all chronic diseases the prevalence of type-2 diabetes mellitus (T2DM) is reaching epidemic proportions and is expected to rise to 366 million by 2030 [3].

The advocacy of exercise therapy in the prevention and management of type- 2 diabetes has been well documented [4, 5]. Regular exercise improves patient's quality of life, modifies abnormal lipid, improves plasma glucose and exercise tolerance, reduces cardiovascular related morbidity and mortality among individuals with type-2 diabetes [5]. Despite conclusive evidence there is underutilisation of exercise among patients [6]. Most patients assume lifestyle modifications as healthy eating and do not exercise regularly [7]. There is also a lack of knowledge and negative attitude of patients towards exercise [8, 9]. Physical activity levels are unsatisfactory among patients and there is a need to encourage patients to undertake regular physical activity for optimal health [9-11].

Aim and objectives: This study was aimed to investigate the knowledge, attitude and practice of exercise among patients with type- 2 diabetes mellitus and to determine the challenges faced by patients in their practice.

\section{Materials and methods}

This cross-sectional study recruited 165 patients with T2DM using convenience sampling technique. They were receiving treatment at the Medical Outpatient Department in Vinayaka Mission's Kirupananda Variyar Medical College Hospital in Salem, Tamil Nadu.

Inclusion criteria: Type- 2 diabetes mellitus patients above 30 years.

Exclusion criteria: All who do not meet the inclusion criteria and patients with physical disability or other chronic conditions that influence physical activity like stroke and cancer.

\section{Assessment of physical characteristics and plasma blood glucose}

Anthropometric characteristics such as height and weight were measured using a graduated height metre and a bathroom weighing scale respectively. The body mass index (BMI) was also calculated (BMI = weight $(\mathrm{kg}) /$ height $(\mathrm{m})^{2}$. The values of recent FBG and $\mathrm{HbA1C}$ were obtained from records.

\section{Assessment of socioeconomic status}

Socio economic status was calculated using the modified Kuppuswamy scale Jan 17 [12]. It is calculated using education, present occupation of the head of the family and the family income.

\section{Assessment of knowledge attitude and practice of exercise}

All patients were made to answer a questionnaire. The questions for the questionnaire are compiled from IPAQ-short form (IPAQ research committee 2005) [13], SKILLD questionnaire [8, 9, 14].

There were two sections in the questionnaire. Section A sought information on socio-demographic and clinical characteristics of the respondents which includes age, sex, marital status, family setting, cardiovascular parameters and the recent fasting blood sugar and HbA1C. Section B sought questions on knowledge, attitude, and pattern of exercise practice for plasma blood glucose control. Items on knowledge consisted of questions which included importance of exercise in diabetes, type of exercise for diabetic control, and the duration of exercise. Out of the total score of 14 the respondent was considered to have an adequate knowledge regarding exercise if his score was 10 or more. Items on attitude assessed whether the person enjoyed exercising and if it gave him a sense of well-being, and also if he thought that it interfered with personal responsibilities. A score 4 and more out of a total score of 6 was considered a positive attitude towards exercise. Questions on practice were designed to assess their routine physical activity over a period of a week. Based on the information the respondents were categorised into those with adequate or inadequate physical activity. Finally, the patients were questioned regarding the motivating factors and barriers to physical activity.

\section{Data analysis}

Descriptive statistics of frequency distribution, percentages, mean and standard deviation were used to summarize the socio-demographic, anthropometric and clinical characteristics of the respondents. Inferential statistics of Chi Square 
test of association was used to determine the associations between knowledge of exercise, and gender, socioeconomic status and practice of exercise, practice of exercise and glycaemic control. Alpha level was set at $\mathrm{p}<0.05$.

\section{Results}

Among the 165 respondents in the study, 85(51.5\%) were men, and $80(48.48 \%)$ were woman. About a third, 54(32.7\%) of the respondents were unskilled or semiskilled workers and a majority, $139(84.2 \%)$ were married individuals. About two thirds, $112(67.9 \%)$ were educated beyond primary school whilst about half, 76(46.1\%) were in the low socioeconomic status class. The mean age was $51.9 \pm 9.7$ years, whilst the mean body weight and body mass index (BMI) were $67.5 \pm 8.7 \mathrm{~kg}$ and $24.5 \pm 2.8 \mathrm{~kg} / \mathrm{m}^{2}$ respectively. The mean random blood glucose RBG as at the time of this survey was $130 \pm 45 \mathrm{mg} / \mathrm{dl}$ whilst the systolic and diastolic blood pressure were $130 \pm 7$ and $88 \pm 9 \mathrm{~mm}$ Hg respectively.
A total of $130(78.8 \%)$ had a knowledge score of 10 or more reflecting a good knowledge of the importance of exercise. A total of $133(80.6 \%)$ respondents had an attitude score of 4 or more reflecting a positive attitude towards physical activity. A total of $95(57.6 \%)$ respondents had adequate physical activity levels.

Table 1 shows the test of association between knowledge of exercise and each of the respondents' sex socioeconomic status and practice of exercise. The results showed that there was no significant association between the knowledge of exercise and the gender $\left(X^{2}=1.3332\right)$ and socioeconomic status $\left(X^{2}=4.0436\right)$ and that there is significant association between knowledge and practice of exercise $\left(X^{2}=29.732\right)$ at $p<0.05$. Table 2 shows the test of association between practice of exercise and glycaemic control. The result showed that there was significant association between practice of exercise and glycaemic control $\left(X^{2}=4.7516\right)$ at $\mathrm{p}<0.05$.

Table 1: Test of association between knowledge of exercise and each of the respondents' sex socioeconomic status and practice of exercise.

\begin{tabular}{|c|c|c|c|c|}
\hline Variable & Good knowledge & Poor knowledge & Chi-square & Pvalue \\
\hline Gender & & & 1.3332 & 0.248232 \\
\hline Male & 70 & 15 & & \\
\hline Female & 60 & 20 & & \\
\hline SES & & & 4.0436 & 0.132416 \\
\hline Upper & 10 & 2 & & \\
\hline Middle & 45 & 32 & & \\
\hline Lower & 40 & 36 & & \\
\hline Physical activity & & & 29.732 & 0.00001 \\
\hline Adequate & 89 & 6 & & \\
\hline Inadequate & 41 & 21 & & \\
\hline
\end{tabular}

Table 2: Test of association between practice of exercise and glycaemic control.

\begin{tabular}{|c|c|c|c|c|c|c|}
\hline Glycaemic control & $\begin{array}{l}\text { Adequate } \\
\text { activity }\end{array}$ & physical & $\begin{array}{l}\text { Inadequate } \\
\text { activity }\end{array}$ & physical & Chi-square & Pvalue \\
\hline Good (HbA1c<7) & 57 & & 30 & & 4.7518 & 0.02927 \\
\hline Poor (HbA1C>7) & 38 & & 40 & & & \\
\hline
\end{tabular}

The factors motivating physical activity and barriers to it were enquired. Among those with adequate physical activity $90(94.7 \%)$ of them said they exercised because they wanted to stay healthy and $5(5.3 \%)$ said it was part of their daily routine. Among patients with good knowledge and low physical activity 25(71.4) quoted lack of time, $8(22.9 \%)$ quoted lack of energy, $1(0.6 \%)$ quoted fear of hypoglycaemic episodes and $1(0.6 \%)$ quoted lack of facilities, citing poor road conditions. 


\section{Discussion}

The overall beneficial effects of exercise in type 2 diabetes are well documented with regard to plasma blood glucose control and multiple cardiovascular risk reduction $[15,16]$. This study found that a large number of the respondents demonstrated good knowledge of exercise for plasma blood glucose control. Nevertheless, there is still significant knowledge deficit about the importance of exercise and as well as reduced level of awareness of the benefits of exercise and this may be due to inadequate health education. Other contributing factor is sole reliance on drugs as the main treatment approach for plasma blood glucose control. Some studies have identified the essence of education through health care providers as key to improving knowledge [17, 18].

The finding in this study is similar to that of Awotidebe et al [9], Mukhopadhyay et al [19] and Kumar [20] who reported respondents had average knowledge regarding exercise, diet and foot care. On the other hand, Okolie et al [21] and Odili et al [22] reported that patients with T2D demonstrate low or very poor knowledge of exercise and self-care practices.

This study showed that $80.6 \%$ had a positive attitude towards physical activity. This is similar to the findings of Kumar [20] and contrary to the findings of Awotidebe TO et al [9] who found predominantly negative attitude.

Knowledge of exercise was significantly associated with practice of exercise. The association of knowledge with practice lent credence to the growing body of evidence in literature that good knowledge can translate into healthy lifestyle practices including exercise [23]. Exercise as non-pharmacologic approach has been reported to be effective for plasma blood glucose control $[15,24]$. Our finding is consistent with findings from previous studies that there is significant association of knowledge with practice [25]. However, our finding is at variance with that of Nikhil et al [26] who reported that there was no significant association between knowledge and practice of exercise.

This study found no significant association between knowledge and gender, and socioeconomic status, which is contrary to the previous studies $[9,27]$.
This study found significant association between physical activity and glycaemic control. This finding is similar to previous study by Boule et al [28] and contrary to study by Shazwani et al [10] which found association only in older age group.

\section{Conclusion}

This study found physical activity levels to be unsatisfactory in about half the respondents. Most of them demonstrated a good knowledge regarding physical activity, but there is significant knowledge deficit, with more than a fifth of them demonstrating poorknowledge. Low physical activity was associated with poor glycaemic control. Thus, there is a need to promote regular physical activity among patients to obtain optimal glycaemic control and to prevent diabetic complications.

\section{Recommendations}

Periodic health education and follow up by health care workers trained and educated in diabetes would be necessary to motivate patients to adopt healthy life style changes. Patients should be followed up to find out if they are able to implement life style changes efficiently. Any challenges faced should be addressed and counselled accordingly.

\section{Conflict of interest}

The author declares no conflicts of interest.

\section{References}

[1] Murray CJI, Lopez AD. Global mortality, disability and the contribution of risk factor: global burden of disease study. Lancet. 1997; 349(9063):1436-1442.

[2] Lloyd-Jones D, Adams RJ, Brown TM, Carnethon M, Dai S, et al. Heart disease and stroke statistics - 2010 update. A report from American Heart Association. Circulation. 2010; 121(7):e1-70.

[3] Wild S, Roglic G, Green A, Sicree R, King H. Global prevalence of diabetes- estimates for the year 2000 and projections for 2030. Diabetes care. 2004; 27(10):1047-1053.

[4] World Health Organisation. Global health risks. In: Mortality and burden of disease attributable to selected major risks: 2009. Available at http:/www.who.int/healthinfo/global_ burden_disease

[5] Kingwell BA, Formosa M, Muhlmann M, Bradley SJ, Mcconell GK. Type 2 diabetic individuals have impaired leg blood flow responses to exercise: role of endothelium-dependent vasodilation. Diabetes care 2003; 26(3):899-904.

[6] Morey M, Dubbert PM, Doyle M, MacAller H, Crowley GM, et al. From supervised to unsupervised exercise: factors associated with exercise adherence. J Aging Phys Act. 2003; 11(3):351-368. 
[7] AE Umeh, L Nkombua. A study of the knowledge and practice of lifestyle modification in patients with type 2 diabetes mellitus in Middelburg sub-district of Mpumalanga. J S African Family Practice. 2017; 60(1):26-30.

[8] Zeb A, Khan M, Wahab F, Khan MT, Nawaz A, et al. Knowledge attitude and practice of diet and exercise among diabetic patients for normal plasma glucose level. Int J Sci Res pub. 2017; 7(1):131-135

[9] Awotidebe TO, Adedoyin RA, Afolabi MA, Opiyo R, et al. Knowledge attitude and practice of exercise for plasma glucose control among patients with type- 2 diabetes. Diabetes Metab Syndr. 2016; 10(2 Suppl 1):S1-6.

[10] Shazwani MNN, Suzana S, Mastura YH, Lim CJ, Teh SC, et al. Malays J Nutr. 2010; 16(1):101-112.

[11] Nelson KM, Reiber G, Boyko EJ, NHANES III. Diet and exercise among adults with tyoe 2 diabetes. Diabetes Care. 2002; 25(10):1722-1728.

[12] Singh T, Sharma S, Nagesh S. Socio-economic status scales updated for 2017. Int J Res Med Sci. 2017; 5(7):3264-3267.

[13] IPAQ Research Committee (2005). Guidelines for data processing and analysis of International Physical Activity Questionnaire (21 $1^{\text {st }}$ Dec 2005).

[14] Rothman RL, Malone R, Bryant B, Wolfe C, Padgett P, et al. The spoken knowledge in low literacy in diabetes scale: a diabetes knowledge scale for vulnerable patients. Diabetes Educ. 2005; 31(12):215-224.

[15] Sigal RJ, Wasserman DH, Kenny GP, Castaneda C. Physical activity/exercise and type 2 diabetes. Diabetes Care 2004; 27(10):2518-2539.

[16] Marwick TH, Hordern MD, Miller T, Chyun AD, Bertoni AG, et al. Exercise training for type 2 diabetes mellitus: impact on cardiovascular risk: a scientific statement from the American Heart Association. Circulation. 2009; 119(25):3244-3262.

[17] Mehta RS, Karki P, Sharma SK. Risk factors, associated health problems, reasons for admission and knowledge profile of diabetes patients admitted in BPKIHS. Kathmandu Univ Med J 2006; 4(1):11-23.

[18] Van Zyl DG, Rheeder P. Survey on knowledge and attitudes regarding diabetic in patient management by medical and nursing staff at Kalafong hospital. JEMDSA 2008; 13(3):9097.

[19] Mukhopadhyay P, Bhaskar P, Debasis D, Nilanjan S, Rachna M. Perceptions and practices of type 2 diabetes: a crosssectional study in a tertiary care hospital in Kolkata. Int J Diabetes Dev Count 2010; 30(3):143-149.

[20] Kumar JP. Knowledge and attitude of diabetic patients regarding diabetic diet, exercise and foot care. Int I Nurs Educ 2012; 4(2):141-145.

[21] Okolie VU, Ehiemere OI, Iheanacho NP, Kalu-Igwe IN. Knowledge of diabetes management and control by diabetic patients at Federal Medical Center Umuahia, Abia State, Nigeria. Int J Med Med Sci 2009; 1(9):353-358.

[22] Odili VU, Isiboge PD, Eregie A. Patients' knowledge of diabetes mellitus in a Nigerian city. Trop J Pharma Res 2011; 10(5):637-642.

[23] Roberts K. Data sources: knowledge of and attitudes to healthy eating and physical activity. Oxford: National Obesity Observatory; 2010.

[24] Ivy JL. Exercise physiology and adaptations to training. In: Ruderman N, Devlin JT, Schneider SH, Kriska A, editors. Handbook of exercise in diabetes. 2nd ed., Alexandria, VA: American Diabetes Association; 2002. pp.23-62.

[25] Kiberenge WM, Ndegwa ZM, Njenga EW, Muchemi EW. Knowledge, attitude and practices related to diabetes among community members in four provinces in Kenya: a cross sectional study. Pan Afr Med J. 2010; 7:2.
[26] Nikhil PH, Shivaswamy MS, Sanjay K, Shweta P, Hiremath MB. Knowledge, attitude and behaviour regarding self-care practices among type 2 diabetes mellitus patients residing in an urban area of South India. Int Multidis Res J 2012; 2(12):31-35.

[27] Heisler M, Bouknight RR, Hayward RA, Smith DM, Kerr EA, et al. The relative importance of physician communication, participatory decision-making, and patient understanding in diabetes self-management. J Gen Intern Med 2002; 17(4):243-252.

[28] Boulé NG, Haddad E, Kenny GP, Wells GA, Sigal RJ. Effects of exercise on glycemic control and body mass in type 2 diabetes mellitus: a meta-analysis of controlled clinical trials. JAMA. 2001; 286(10):1218-1227. 